\title{
Nutrition knowledge and care practices of home-based caregivers in Vhembe District, South Africa
}

\author{
Tirhani A Masia ${ }^{1}$, Lindelani F Mushaphi ${ }^{1}$, Ngoako S Mabapa ${ }^{1}$, Xikombiso G Mbhenyane ${ }^{2,3}$
}

1. University of Venda, School of Health Sciences, Department of Nutrition, P/bag X5050, Thohoyandou, 0950, South Africa; Email: Tel: 015962 8906, Fax: 086771 1292. Tirhani.masia@univen.ac.za;

Lindelani.mushpahi@univen.ac.za; solomon.mabapa@univen.ac.za

2. Stellenbosch University, Faculty of Medicine and Health Science, Division of Human Nutrition, P.O.Box 241, Cape Town, 8000, South Africa; Email: xgm@sun.ac.za, Tel: 021938 9135, Fax: 0219332991.

\begin{abstract}
Background: Home-based care is provided to clients in their homes to promote and maintain good health, hygiene and nutrition.

Objective: This study assessed nutrition knowledge and care practices of home-based caregivers in Vhembe District, South Africa.

Methods: The design was cross sectional, descriptive and exploratory using quantitative and qualitative approaches. Multistage sampling was used, with convenient selection of two municipalities from four, eight home-based care agencies randomly selected from 96 agencies, 128 caregivers conveniently selected for interviews, 92 caregivers selected for focus group discussions and 28 caregivers selected for observation during home visits. Demographic characteristics, nutrition knowledge and care practices were evaluated using questionnaires, interview guides and observational checklists. Data were analysed using SPSS 22 and thematic analysis for qualitative data.

Results: caregivers (99.2\%) were women, 68.7\% had secondary education and all had received 59-day training and $64.1 \%$ had six to ten years of home-based care experience. Only $0.8 \%$ had adequate nutrition knowledge, $45.3 \%$ satisfactory knowledge and 53.9\% limited to no knowledge. Most care practices reported during the focus group discussions were not observed during home visits.

Conclusion: Nutrition knowledge and care practices of HBC in Vhembe District were found to be inadequate. The nutrition content in the training package should be improved.

Keywords: Nutrition knowledge; nutrition care practices; home-based care; home-based caregivers.

DOI: https://doi.org/10.4314/ahs.v20i2.46

Cite as: Masia TA, Mushaphi LF, Mabapa NS, Mbhenyane XG. Nutrition knowledge and care practices of home-based caregivers in Vhembe District, South Africa. Afri Health Sci. 2020; 20(2): 912-922. https:// doi.org/10.4314/ abs.v20i2.46
\end{abstract}

\section{Introduction}

Home-based care (HBC) is the provision of healthcare services by formal caregivers (healthcare professionals) and informal caregivers (home-based or family caregivers) in the client's home. Home-based care focusses on the promotion, restoration and maintenance of a per-

\section{Corresponding author: \\ Xikombiso G Mbhenyane, Stellenbosch University, Faculty of Medicine and Health Science, Division of Human Nutrition, P.O.Box 241, Cape Town, 8000, South Africa; \\ Tel: 0219389135 , \\ Fax: 0219332991. \\ Email:xgm@sun.ac.za}

son's maximum level of comfort, function and health, including care towards a dignified death. ${ }^{1}$

Nutrition has been recognised globally as a major lifestyle factor in health promotion and is important in the prevention and management of chronic diseases. ${ }^{1,2}$ The World Health Organization (WHO) ${ }^{3}$, indicated that home-based caregivers play a vital role in mobilising communities to access nutrition care services and to provide hope through high-quality and appropriate care, that helps patients and their families to maintain independence and improve quality of life.

According to the $\mathrm{WHO}^{4}$, public health services in developing countries are of poor quality due to diminishing resources and high costs associated with private healthcare. HBC in developing countries, is the most common type of healthcare that people living with HIV and AIDS (PLWHA) received $^{5}$, since primary healthcare 
services are not necessarily accessible or affordable. The $\mathrm{WHO}^{7}$ further reported that globally healthcare resources are being depleted due to the growing number of patiens who seek medical care; approximately $90 \%$ terminally ill patients are cared for at home. Therefore; $\mathrm{HBC}$ is expanding globally due to increasing needs for a transformation from hospital-based care to home-based and community care, for economic reasons. Healthcare institutions, especially in developing countries, are overflowing with PLWHA. ${ }^{7}$. Therefore, organisations and governments have consistently recommended the HBC approach for PLWHA. ${ }^{8}$

The WHO7 provided a framework for the implementation of $\mathrm{HBC}$ with specific roles for healthcare systems at national, provincial, district and community levels. The South African government adopted this framework and implemented it as part of the primary healthcare system. The South African Department of Health developed a learner handbook for the training of home-/ community-based caregivers in view of equipping them to work as a member of a healthcare team, providing home care, education and support to clients and their families. ${ }^{9}$ The component of nutrition is one of the 12 sections that were included in the learner handbook and it aimed to provide home-based caregivers with the knowledge of sound nutritional principles. These principals included the three food groups and management of nutrition-related problems, such as nausea and vomiting, weight loss, diarrhoea and swallowing difficulties.

According to Given et al. ${ }^{10}$, caregivers lack confidence and feel unprepared to provide sustained HBC for people with chronic diseases, as they do not have the necessary knowledge and skills. Lack of knowledge among caregivers has been reported as the most important contributing factor to poor quality care. ${ }^{11}$ The ability of caregivers to provide quality care and contribute to the management of diseases is vital, as it will assist with the maintenance of clients' nutritional status and improve their quality of life.

One of the components of $\mathrm{HBC}$ is to provide nutritional care and support to clients. Studies assessing nutrition knowledge have been conducted among formal caregivers who are known as healthcare professionals ${ }^{12}$ in North America. ${ }^{13}$ However, little information is available on nutrition knowledge and care practices of caregivers in sub-Saharan Africa. ${ }^{14}$ Studies conducted in Vhembe District, South Africa, have indicated that caregivers gained sufficient knowledge about HBC services during training ${ }^{15}$ but little knowledge on the man- agement of chronic diseases, minor ailments and counselling. ${ }^{11}$ Moreover, none of these studies in Vhembe District assessed the nutrition knowledge and care practices of caregivers.

To address this gap in the literature, the aim of this study was to assess the nutrition knowledge and care practices of home-based caregivers in Vhembe District. The specific objectives of this study were to assess caregivers' nutrition knowledge, to determine their nutrition care practices, and to identify factors that influence their nutrition knowledge and care practices.

\section{Methods}

The study was a cross-sectional, descriptive and exploratory design and used quantitative and qualitative approaches. Multistage sampling was employed. The study was conducted among caregivers from two conveniently selected form four municipalities in Vhembe District, Limpopo province, South Africa. There were $46 \mathrm{HBC}$ agencies in Municipality one, and $50 \mathrm{HBC}$ agencies in Municipality two. A list of all HBC agencies was received from the district office. Systematic random sampling was used to select eight HBC agencies from 96 agencies, four from each municipality that served as the sampling frame. Letters to recruit caregivers were distributed to the selected agencies and explained the research purpose and procedures, including confidentiality issues. Participation was voluntary and caregivers were informed that they were entitled to withdraw consent at any point during the research. A total of 128 caregivers consented and agreed to participate in the study. Furthermore, subsamples of 92 and 28 caregivers were randomly selected for focus group discussions and home visit observations, respectively.

Data were collected in three stages: interviews, focus groups and observations. A researcher-administered questionnaire was used to collect quantitative data, while an interview guide and observation checklist were used to collect data. A questionnaire was developed in English in consultation with a language expert from the Centre for African Languages at the University of Venda and translated into the local languages (Tshiven$\mathrm{da}$ and Xitsonga). The questionnaire included sections aimed at collecting socio-demographic data and determining nutrition knowledge. The nutrition knowledge of caregivers was tested using questions based on the South African Food-Based Dietary Guidelines16 and the learners' handbook for home-based caregiver training. 9 The test consisted of 11 multiple-choice questions with four possible answers each. 
An interview guide and observational checklist were used for gathering qualitative data on nutrition care practices. During focus group discussions, attention was paid to the care provided to clients and the training and support that caregivers received. Eight focus group discussions were conducted, and each group consisted of 9-12 caregivers. Home visits were conducted by the project leader accompanying 28 home-based caregivers on home visits to 65 of their clients. The following aspects were focused on during observations: personal hygiene of caregivers, proper food-handling practices, environmental hygiene and provision of nutrition education.

For data verification and quality control purposes, only regulatory authorities and/or the research team could access the data under conditions of strict confidentiality. To ensure anonymity of the home-based caregivers, codes instead of names were used for identification.

Given the fact that some caregivers had lower levels of education, a researcher-administered questionnaire was used to collect data, thus improving the reliability of the data collected. Furthermore, the interviews were conducted by the same researcher, who is proficient in the two local languages used.

A pilot study comprising five caregivers who were not included in the main study was conducted to ascertain the clarity of the questions. The questionnaire was subjected to both face and content validity. Comments regarding the content validity of the questionnaire were requested from researchers of the Department of $\mathrm{Nu}-$ trition at the University of Venda. Face validity was tested during the pilot study. Experts in the fields of nutrition and HBC in Vhembe District were also consulted. Based on their suggestions, minor alterations were made to the phrasing of the questions.

\section{Ethical considerations}

Ethical approval for the study was obtained from the Higher Degrees Committee of the University of Venda as mandated and ratified by the Research and Ethics
Committee (SHS/10/NUT/001). Permission to conduct the study was obtained from the provincial and district Department of Health and HBC agencies. All home-based caregivers who participated in the study signed an informed consent form after a comprehensive explanation of the study had been provided. Furthermore, all clients visited were requested to provide consent in writing and a verbal assent was requested from other persons in the household on the day of the visit. Participating home-based caregivers did not benefit directly from the study and no risks were involved.

\section{Data analysis}

Quantitative data were analysed using SPSS version 22 and qualitative data via thematic analysis. ${ }^{17}$ A Likert scale was developed to assess the level of caregivers' nutrition knowledge and was interpreted as follows: a score of 0-7 indicated none to limited nutrition knowledge, 8-10 indicated satisfactory knowledge and 11 (all correct) indicated adequate knowledge. The relationship between demographic variables and level of nutrition knowledge was determined by using the chi-square $\left(\mathrm{x}^{2}\right)$ test at $95 \%$ confidence level with a significance level of $\mathrm{p}<0.05$. The variables used to explore relationships were marital status, education level, tertiary qualifications, nutrition training received and years of HBC experience.

\section{Results}

\section{Socio-demographic data}

Almost all the participating caregivers ( $n=127,99.2 \%)$ were women. The majority ( $\mathrm{n}=82,84.3 \%$ ) of the caregivers were between the ages of 30 and 50 years. More than half $(n=69,53.9 \%)$ of the caregivers completed secondary school education (Grades 11-12) and only $(n=23) 18 \%$ completed tertiary education. The results of the study also revealed that $(n=121) 94.5 \%$ of the caregivers received nutrition training and $(n=82) 64.1 \%$ had 6-10 years of working experience as caregivers (Table 1). 
Table 1: Demographic information of participating caregivers $(n=128)$

\begin{tabular}{|l|l|l|}
\hline Variables & Frequency $(\mathbf{n}=\mathbf{1 2 8})$ & $\mathbf{\%}$ \\
\hline Sex & & \\
\hline Male & 1 & 0.8 \\
\hline Female & 127 & 99.2 \\
\hline Age (years) & & \\
\hline$<30$ & 8 & 6.3 \\
\hline $30-40$ & 62 & 48.4 \\
\hline $41-50$ & 46 & 35.9 \\
\hline$>50$ & 12 & 9.4 \\
\hline Marital status & & \\
\hline Married & 78 & 61.0 \\
\hline Single & 50 & 39.0 \\
\hline Education level & & \\
\hline Never attended school & 4 & 3.1 \\
\hline Grade 1-4 & 8 & 6.3 \\
\hline Grade 5-7 & 5 & 3.9 \\
\hline Grade $8-10$ & 19 & 14.8 \\
\hline Grade 11-12 & 69 & 53.9 \\
\hline Tertiary level & 23 & 18.0 \\
\hline Type of qualification $(\boldsymbol{n}=30)$ & & \\
\hline Office administration & 15 & 11.7 \\
\hline Educator (foundation phase) & 6 & 4.7 \\
\hline Welfare/cook & 7 & 5.5 \\
\hline Technician/artisan & 2 & 1.6 \\
\hline Years of home-based care experience & & \\
\hline $1-5$ & 24 & 18.7 \\
\hline $6-10$ & 82 & 64.1 \\
\hline$>10$ & 22 & 17.2 \\
\hline & & \\
\hline
\end{tabular}

\section{Nutrition Training}

Caregivers indicated that they received nutrition training when they attended the 59-day and Ancillary Health Care training courses.9 Training was mainly facilitated by professional nurses and only $(n=9) 7.1 \%$ of the caregivers indicated that they received nutrition information from nutrition professionals. The information received ranged from nutrients to physical activity (Table 2). In addition to the training, caregivers received financial support, social services, food parcels and toys for children from various organisations.

Table 2: Nutrition training Information

\begin{tabular}{|c|c|c|}
\hline Variables & Number $(n=128)$ & Percent $(\%)$ \\
\hline \multicolumn{3}{|l|}{ Received training about nutrition } \\
\hline Yes & 121 & $94.5 \%$ \\
\hline No & 7 & 5.5 \\
\hline \multicolumn{3}{|l|}{ Sources of information } \\
\hline Nurses & 76 & 59.4 \\
\hline Home-based caregivers & 15 & 11.7 \\
\hline Nurses \& home-based caregivers & 10 & 7.8 \\
\hline Dietitians or Nutritionists & 9 & 7.1 \\
\hline Representatives from Center for Positive Care & 7 & 5.5 \\
\hline Educators & 4 & 3.1 \\
\hline \multicolumn{3}{|l|}{ Type of information received } \\
\hline Nutrients & 111 & 86.7 \\
\hline Food groups & 54 & 42.2 \\
\hline Food handling and preparations & 30 & 23.4 \\
\hline Personal hygiene & 19 & 14.8 \\
\hline Management of diseases & 9 & 7.8 \\
\hline Environmental hygiene & 6 & 4.7 \\
\hline Physical activity & 3 & 2.3 \\
\hline
\end{tabular}




\section{Provision of nutrition and education to clients}

Almost all caregivers $(n=122,95.3 \%)$ indicated that they came to know that people needed their services during door-to-door campaigns; $(\mathrm{n}=94) 73.3 \%$ were informed via referrals from clinics and $25 \%$ were in- formed by relatives and/or friends of clients, while $(\mathrm{n}=$ 30) $23.4 \%$ were approached by clients themselves. The caregivers cared for clients with different types of conditions (Figure 1). The number of clients visited varied from three to seven and time spent ranged from 30 to 90 minutes, depending on the care to be provided.

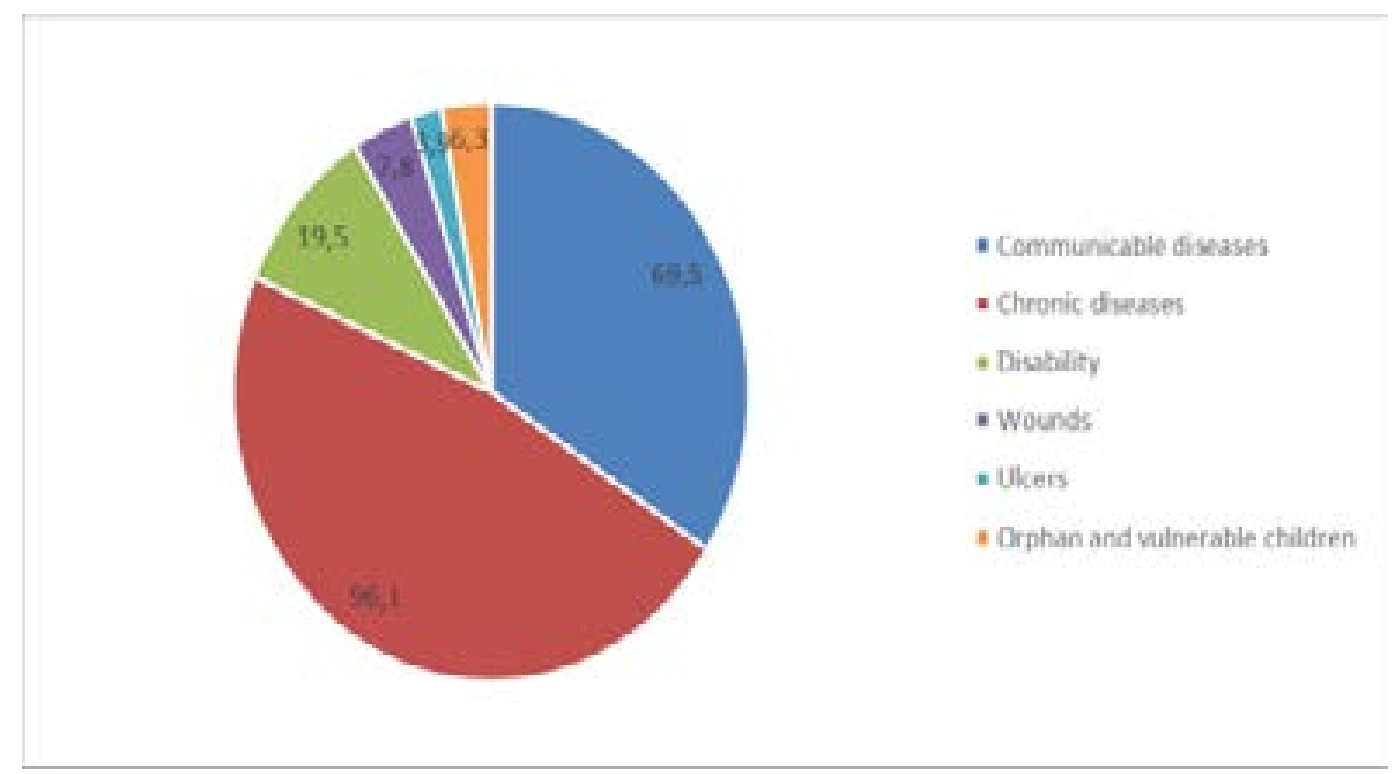

Figure 1: Types of clients' conditions cared for by caregivers in percentages $(\%)(\mathrm{n}=128)$

Caregivers were asked open-ended questions based on the South African Food-Based Dietary Guidelines16 to assess their nutrition knowledge. The majority $(n=122,95.3 \%)$ of the caregivers correctly identified starchy foods as the basis of most meals. Some caregivers $(n=74,57.8 \%)$ also knew that they had to advise their clients to consume legumes and beans regularly, since these are good sources of protein. Few of the caregivers $(n=7,5.5 \%)$ indicated that protein of animal origin could be eaten daily. Almost all caregivers knew that fat $(n=127,99.2 \%)$, salt $(n=126,98.4 \%)$ and sugar $(n=125,97.7 \%)$ should be used spaingly. All caregivers knew the importance of physical activity and of drinking clean, safe water, with $(n=82) 64.1 \%$ indicating that 6-8 glasses per day is the recommended amount. The majority ( $\mathrm{n}=114,89.1 \%$ ) of the caregivers knew that a balanced diet is composed of a variety of foods that provide various nutrients. Less than half $(\mathrm{n}=56$, $43.8 \%$ ) of caregivers listed all three basic food groups correctly, namely energy, protective and body-building foods. Furthermore, $(n=113) 88.3 \%$ knew that starchy foods provide energy, $(n=109) 85.9 \%$ knew that protein foods are responsible for body building, while ( $\mathrm{n}=$ 105) $82.8 \%$ knew that fruits and vegetables protect the body against diseases.

Most of the caregivers ( $\mathrm{n}=125,97.7 \%)$ knew that soft foods, such as yoghurt, porridge and mashed potato, should be given to clients with swallowing difficulties. Caregivers had knowledge of the appropriate advice to give to clients suffering from weight loss, and nausea and vomiting. The results further revealed that $(\mathrm{n}=$ 88) $68.8 \%$ of caregivers indicated that dehydration is caused by diarrhoea and vomiting. When asked about the treatment for dehydration, $(n=52) 40.6 \%$ of caregivers indicated the use of oral rehydration solution. These caregivers also knew how to prepare this solution and (= 49) $38.3 \%$ indicated that it should be given to a child every time after vomiting or the passing of watery stools. The level of nutrition knowledge of caregivers was further assessed using a knowledge test with eleven questions. The responses to the specific questions are given in Table 3. 
Table 3: Correct responses of caregivers to a nutrition knowledge test $(\mathrm{n}=128)$

\begin{tabular}{|c|c|c|}
\hline Questions and answers & Frequency & $\%$ \\
\hline $\begin{array}{l}\text { 1. What do you advise your clients on fat intake? } \\
\text { - To eat sparingly }\end{array}$ & 128 & 100 \\
\hline 2. Which food should form the basis of most meals? & 122 & 95.3 \\
\hline $\begin{array}{l}\text { 3. Give examples of body-building foods. } \\
\text { - Protein sources }\end{array}$ & 101 & 78.9 \\
\hline $\begin{array}{l}\text { 4. Give examples of protective foods. } \\
\text { - Vitamin \& mineral sources }\end{array}$ & 100 & 78.1 \\
\hline $\begin{array}{l}\text { 5. How often should your clients eat vegetables and fruits? } \\
\text { - Daily }\end{array}$ & 97 & 75.8 \\
\hline $\begin{array}{l}\text { 6. Give examples of energy foods. } \\
\text { - Starch/fat sources }\end{array}$ & 96 & 75.0 \\
\hline $\begin{array}{l}\text { 7. What is the importance of advising clients to eat legumes } \\
\text { (e.g. dried beans) regularly? } \\
\text { - To get protein/to build the body }\end{array}$ & 69 & 53.8 \\
\hline $\begin{array}{l}\text { 8. What are the three basic food groups? } \\
\text { • Energy food, body-building food and protective food }\end{array}$ & 56 & 43.8 \\
\hline $\begin{array}{l}\text { 9. What nutrition advice do you give to people suffering from } \\
\text { nausea and vomiting? }\end{array}$ & \multirow[t]{2}{*}{55} & \multirow[t]{2}{*}{43.0} \\
\hline $\begin{array}{l}\text { a. Eat small, frequent meals } \\
\text { b. Stay away from bad cooking odour } \\
\text { c. Eat before taking medication }\end{array}$ & & \\
\hline $\begin{array}{l}\text { 10. How do you prepare oral rehydration solution? } \\
\qquad \mathbf{1} \text { litre boiled water }+8 \text { level teaspoons sugar }+1 / 2 \text { level } \\
\text { teaspoon salt }\end{array}$ & 52 & 40.6 \\
\hline $\begin{array}{l}\text { 11. What nutrition advice do you give to people suffering from } \\
\text { weight loss? } \\
\text { a. Eat starchy and fatty foods to regain weight } \\
\text { b. Eat small meals more often } \\
\text { c. Avoid drinking with meals }\end{array}$ & 40 & 31.2 \\
\hline
\end{tabular}

The overall responses on nutrition knowledge revealed that $(\mathrm{n}=69) 53.9 \%$ of the caregivers had none to no nutrition knowledge, while $(\mathrm{n}=58) 45.3 \%$ had satisfactory knowledge and $(\mathrm{n}=1) 0.8 \%$ had adequate knowledge, as depicted in Figure 2. The relationship between so- cio-demographic variables and level of nutrition knowledge was determined, but no significant correlation was found. The results were as follows: marital status $(\mathrm{p}=$ $0.36)$, education level $(p=0.06)$, tertiary qualification ( $p$ $=0.17)$, nutrition training $(\mathrm{p}=0.22)$ and HBC experience $(p=0.83)$. 


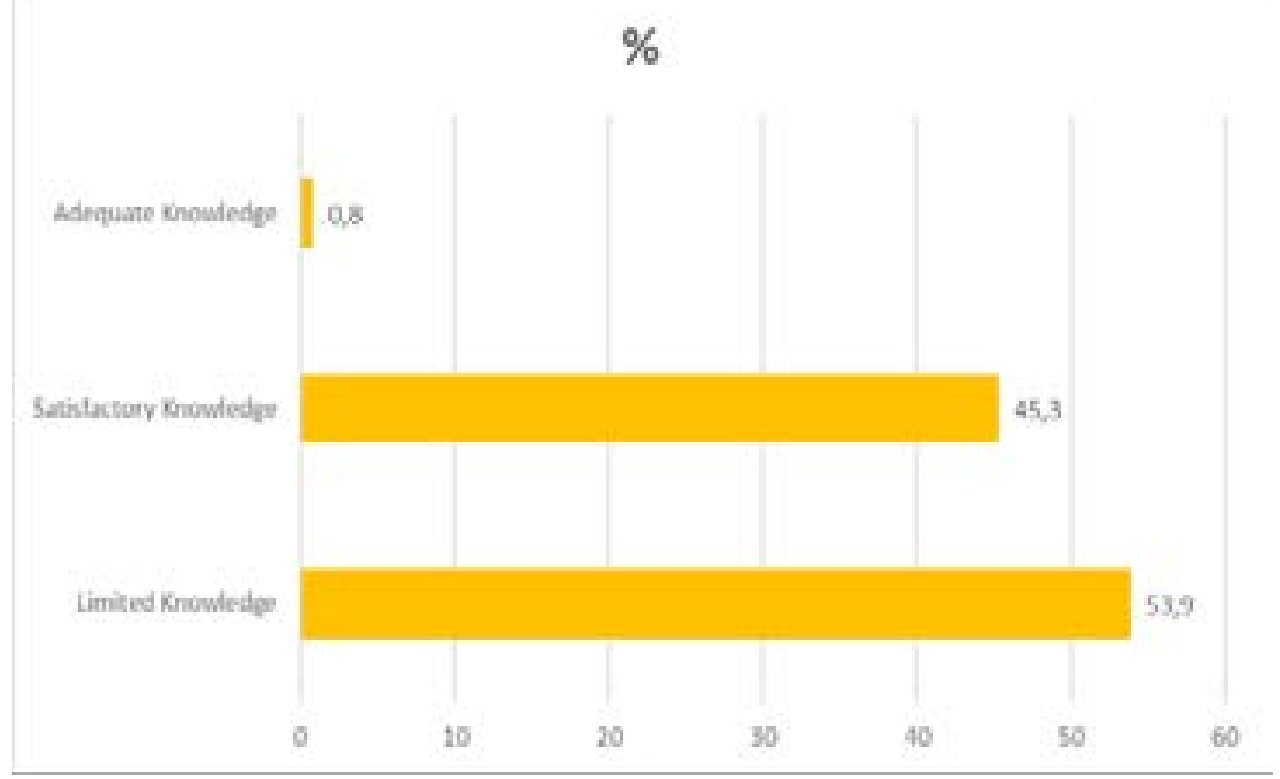

Figure 2: Distribution of nutrition knowledge scores $(\mathrm{n}=128)$

\section{Implementation of nutrition care practices}

Nutrition care practices were established using qualitative methods. The findings on nutrition care practices were based on the data gathered during focus group discussions and observations.

The themes that were generated from the focus group discussions were: training and skill development of caregivers; support programmes available for caregivers; care given to clients with subthemes of mental ill clients, clients living alone, bedbound clients, clients with chronic diseases, clients with communicable diseases and vulnerable groups such as orphans; nutrition education; assistance to clients with subthemes of food, shelter and clothes.

On the training, all home-based caregivers reported that they received a 59-days training and three year Ancillary Health Care course from level 1 to 4 that was offered by the Department of Health. The content covered included food groups, management of different types of diseases such as hypertension, diabetes Mellitus, HIV and AIDS and TB, first aid, use of road to health booklet (RtHB), breastfeeding, bed making, caring for clients and HBC services. All home-based caregivers indicated that the training they received were not enough to keep them updated with current information especially on nutrition because they received nutrition information when being trained on chronic diseases, HIV and AIDS, TB and infant feeding. Therefore, home-based caregivers suggested that refresher courses more often would keep them up to date.

Home-based caregivers described the care given to cli- ents during home visits and they all reported that the care was tailor made according to clients' conditions. Home-based caregivers of agency 8 reported that they assisted their clients with cleaning, bathing, washing, feeding and administering medication only if they were given permission to do so by clients and/or family members. In addition, agency 5 and 8 indicated that they demonstrate to family members on how to care for clients, for them to learn and assist in their absence. Home-based caregivers of agency 1 indicated that having prayer sessions before and after working gave their clients and families more strengths and hope of being healed.

On nutrition education they gave to clients, caregivers indicated that they advised clients with weight loss to consume protein-rich foods, such as mopani worms, eggs, milkfish and meat, to increase their body weight and build muscle tissue. One caregiver said the following "The amount of nutrients in food depends on the type of food. For example, the nutrients that are responsible for body building in fruit juice are in low amounts, while those for protection against diseases are in high amounts. Fruits and vegetables are responsible for protecting the body against diseases as they have vitamins such as vitamin B1". Regarding indigenous dishes and foods, one caregiver said the following "We encouraged our clients to prepare indigenous dishes, such as traditional samp or bean/nuts dish and pumpkin dish, because they are cheap, accessible and healthy and they build the body and protect against diseases". Other indigenous foods reported to be accessible to cli- 
ents were green leafy vegetables such as Corchorus hirsutus or C. tridens (jute plant), Amaranthus thunbergii (small pig weed), Cucumis hirsutus (pumpkin), Bidens pilosa, Solanum nigrum (night shade) and Cleome gynandra (spider flower); indigenous fruits, such as Carissa grandiflora (natal plum), Diospyros mespiliformis, Berchemia discolor and Ficus sycomorus (fig); and termites. However, in areas where these indigenous foods are abundant, caregivers indicated that clients did not necessarily have access to these foods, since people have demarcated areas for their own use. Other caregivers indicated that they taught their clients about food fortification. Fortified bread is said to be expensive and clients were advised to buy it occasionally. Caregivers knew that fortification involves the addition of nutrients, but they did not know which nutrients are added. One caregiver said: 'Bread contain [sic] starch, which protects the body against diseases' while another caregiver said: 'Starch gives energy as it contained carbohydrate and is obtained from bread and maize meal.'

On assistance to clients, caregivers indicated that clients who lack basic needs (food, shelter and clothing) are referred to the Department of Social Development to be considered for social grants and food parcels, community development workers for shelter, drop-in centres for meals and chiefs/counsellors to enlist them for government low-cost housing. While clients were awaiting assistance, caregivers asked for donations from the community and local churches and advised clients and their families to establish vegetable gardens. In summary, caregivers indicated that they clean, bathe, wash, cook, feed, counsel, collect and administer medication as well as encourage and show family members how to care for the clients.

However, during home visits, the researcher observed that most of the nutrition information that was shared by caregivers was not imparted to clients. The categories that emerged from the observation were practices including personal hygiene of home-based caregivers when caring for clients, hygiene practices in food handling, environmental hygiene as well as the provision of nutrition education. Caregivers were observed in the households, advising clients on personal and environmental hygiene practices and assisting them with meal preparation, bathing, washing, cleaning and exercising (for clients with physical challenges). Very few caregivers were observed washing their hands with soap and wearing gloves before caring for their clients. The caregivers who were observed preparing meals for clients did not rinse utensils before cooking.
Furthermore, the researcher observed that not all clients were taught about nutrition during home visits. The nutrition information taught to a few clients included the consumption of a variety of foods, use of fat, salt and sugar, consumption of fruits and vegetables and restriction of alcohol intake and smoking. Caregivers promoted the consumption of fresh green leafy vegetables because according to their knowledge; its nutrient content of these vegetables was higher than that of dried vegetables. The caregivers further claimed that eating fresh green leafy vegetables boosts the immune system and protects the body against diseases. One HBC agency was located in an area that is rich in fruits and vegetables and caregivers indicated that clients used them for commercial purposes and were advised to consume them daily to improve their health and nutritional status.

Caregivers reported various challenges that hindered the provision of proper care to their clients. Since caregivers did not have in-depth nutrition training, they failed to respond adequately to some nutrition-related questions asked by clients. Caregivers also indicated that it was difficult to care for clients who did not disclose their conditions and who failed to adhere to the recommended treatment and diet, which posed risks to their health. Some of the clients and their families were said to be averse to HBC services, resulting in difficulty for caregivers to advise fmily members on how to care for their loved ones. Furthermore, female caregivers also experienced difficulties when caring for bed-bound male clients.

\section{Discussion}

The training received by caregivers participating in this study was similar to the training offered to caregivers from other agencies. ${ }^{18,19,20}$ Akintola $^{21}$ mentioned that South Africa promotes volunteerism for caregivers, and the Department of Health are required to assist caregivers to obtain formal employment through the training that they have received. Furthermore, the training manual for caregivers in Uganda5 focuses mainly on nutritional care for PLWHA and recommendations were made that South African HBC training manuals need to be reviewed to enable caregivers to gain deeper nutrition knowledge. Nutrition training and support for caregivers also need to be strengthened, as it is pivotal to the provision of optimal nutritional care to clients. Agency coordinators offered ongoing support in the current study, especially to newly appointed caregivers. The findings of Madzingira20 and Rendall-Mkosi and 
Phohole ${ }^{22}$ showed that nutrition experts through ongoing support/training taught emerging nutrition issues to caregivers. Ongoing training, especially on nutrition, will help caregivers gain knowledge and have confidence in assisting clients with their nutritional needs. The results of this study show that very few $(0.8 \%)$ of the caregivers had adequate nutrition knowledge. Similar findings were reported in Kenya, where only 3.4\% of caregivers had adequate nutrition knowledge. ${ }^{19}$ The current results contrast with those of a study conducted in Zimbabwe, where caregivers were knowledgeable on the nutritional needs of their clients.18 The nutrition knowledge of caregivers in this study was not influenced by the selected demographic factors, whereas education level and length of training of caregivers in Kenya were positively related to their nutrition knowledge. ${ }^{19}$ In Zimbabwe, a lack of resources was identified as a factor that hindered caregivers to provide proper nutritional care to their clients, irrespective of their nutrition knowledge. ${ }^{18}$ Thus, training programmes for homebased carers should ensure adequate content on nutrition.

This study revealed that caregivers cared for clients with different conditions, whereas previous studies focused on care for PLWHA. ${ }^{23,24,25}$ The conditions of clients cared for in the present study were similar to those in Zimbabwe ${ }^{22}$ and elsewhere in South Africa. ${ }^{20}$ Similar to clients in other studies, those in the current study were received through referrals from the community, health institutions, social workers ${ }^{20}$ and door-to-door campaigns, whereas some clients contacted the caregiver because of their need for HBC services. ${ }^{22}$ Caregivers should thus be trained to be able to deal with any condition in the household or be equipped with lifelong learning and ability to adopt and adjust processes when required.

Referrals from health institutions were the result of the high number of clients seeking medical services and shortages of healthcare personnel, thereby placing strain on public health services. ${ }^{26}$ The Department of Health ${ }^{27}$ reported that the number of clients visited per day varies from one HBC agency to another. This variation was due to the type of care provided and the distance travelled from one household to the next. In addition, Campbell and Foulis ${ }^{28,29}$ reported that caregivers walk one to several hours to clients' households, whereas those in Zimbabwe were assigned to work in their residential areas to minimise transport cost and long travelling distances. ${ }^{21}$ Long travelling distances were experienced by the researcher in this study during home visit accompaniment. Logistics and travel distances should be a consideration when placing homebased carers. It may be an ideal situation to place them in the same place where they reside, which will enhance their client knowledge and reduce travel distances.

This study focused on nutrition care that includes promotion and maintenance of good health, hygiene and nutrition of clients. Clients in the present study received food parcels from local supermarkets. $\mathrm{T} / \mathrm{span}>$ he researcher observed that the food parcels had expired and could not be distributed to needy clients because of health and food safety concerns. Other agencies provided orphans and vulnerable clients with food parcels, clothes, soap, toys and blankets, as well as health and educational assistance through the organisations that supported them. ${ }^{22}$. It has been reported that the food parcel and school feeding systems were not reaching all clients in desperate need. ${ }^{20}$ The latter resulted in clients losing confidence in HBC services. Tools of trade appropriate for homebased care should be determined and provided in a sustainable manner. The homebased carers should not be dependent on donations to support their clients but rather on the support mechanism embedded in health care resourcing.

Challenges that were reported in this study were similar to those reported previously in Vhembe District ${ }^{14}$ and Kenya. ${ }^{19}$ Other challenges identified from other studies include lack of resources, such as blood pressure monitors and teaching aids, low stipends and lack of transport for long travel distances during home visits. Poor referral systems and lack of proper nutritional support for PLWHA are some of the challenges reported in a previous study. ${ }^{30}$ These challenges should be points of consideration by homebased care agencies and health authorities during resource allocation and planning.

This study found that women who did not appear to have adequate nutrition knowledge mostly rendered HBC services in Vhembe District. Some of the activities that were reported as part of nutrition care practices were rarely observed as being practised during home visits. Care of home-based clients is important to improve their livelihoodsas well as to contribute to the reduction of health services costs. The level of nutrition knowledge of caregivers was not influenced by demographic variables, but their level of nutrition knowledge and the challenges that they experienced, may have influenced their practices. Findings from this study are likely to occur in HBC practices in other rural South 
African local municipalities. Future research should be done in all provinces and the HBC training should be standardised.

\section{Limitations}

The findings are only applicable to the population of caregivers from similar municipalities in terms of development. The home visits were only done once per client, and all were existing HBC clients, making it likely that only routine care was observed and not initial education and counselling as would be expected during the initial visit. Another limitation is that no interviews or any verification was conducted with the caregivers' supervisors or trainers from the HBC agencies. Further research should thus be done with clients when they start the services and should include interviews with the HBC trainers and supervisors.

The study recommends that the government, programme implementers, policy makers and researchers should work together to improve HBC services. Nutrition training should include the South African FoodBased Dietary Guidelines and be facilitated by nutrition professionals/experts to improve the nutrition knowledge of home-based caregivers. Furthermore, refresher couses and continuing education should be implemented on an annual basis.

In conclusion, nutrition education on a healthy diet for clients should be strengthened by providing caregivers with teaching materials such as pamphlets, posters and leaflets and by encouraging them to prepare their lessons. Monitoring and evaluation of HBC practices should be done regularly with emphasis on clients' well-being.

\section{Acknowledgements}

The funding for this research was provided by the $\mathrm{Na}$ tional Research Foundation of South Africa and the University of Venda. The authors would like to thank participating, HBC agencies, home-based caregivers and their clients for their contributions to the success of this study.

\section{Competing interests}

The authors declare that they have no financial or personal relationship(s) that may have inappropriately influenced them in writing this article.

\section{Consent for publication}

All the authors have consented to the publication and agreed that X.G. Mbhenyane submits the paper and be the corresponding author.

\section{References}

1. Pignone MP, Ammerman A, Fernandez L. Counseling to promote a healthy diet in adults: A summary of the evidence for the U.S. Preventive Services Task Force. Am J Prev Med. 2003; 24(1), p.75-92.

2. Tapsell LC, Probst YC. Nutrition in the prevention of chronic disease, in AP Simopoulos, editor. Nutrition and fitness: Cultural, genetic and metabolic aspects: International Congress and Exhibition on Nutrition, Fitness and Health selected proceedings, 2008, Shanghai, China, November-December. 2006; p. 94-105.

3. WHO (World Health Organization). Home-based and long-term care: Home care issues at the approach of the 21 st century from a World Health Organization perspective: Annotated bibliography. WHO, Geneva.

4. WHO (World Health Organization). Home-based long-term care. WHO technical report series 898. WHO, Geneva.

5. Kipp W, Tindyebwa D, Rubaale T, Karamagi E, Bajenja E. Family caregivers in rural Uganda: The hidden reality. Health Care Women Int. 2007; 28(10), p.856-871.

6. Olenja JM. Assessing community attitude towards home-based care for people with AIDS (PWAs) in Kenya. J. Community Health. 1999; 24(3), p.187-199.

7. WHO (World Health Organization). Fact sheets on HIV/AIDS: A desktop reference. WHO, Geneva. 2003. 8. Van Rensburg HCJ. Health and health care in South Africa. Van Schaik, Pretoria. 2004.

9. Department of Health, Comprehensive home/ community-based care training manual; curriculum for the training of community-based home caregivers: A learner handbook for the training of home-community based care, Department of Health. Pretoria. 2001.

10. Given B, Sherwood PR, Given CW. What knowledge and skills do caregivers need? Am J Nurs. 2008; 108(9), p.28-34.

11. Zimba EW, McInerney PA. The knowledge and practices of primary care givers regarding home-based care of HIV/AIDS children in Blantyre (Malawi). Curationis. 2001; 24(3), p.83-91.

12. Schaller C, James EL. The nutritional knowledge of Australian nurses. Nurse Educ Today. 2005; 25(5), p.405412.

13. Crogan NL, Shultz JA, Massey LK. Nutrition knowledge of nurses in long-term care facilities. J Contin Educ Nurs. 2001; 32(4), p.171-176.

14. Farran CJ, Loukissa D, Perraud S, Paun, O. Alzheimer's disease caregiving information and skills. Part II: Family caregiver issues and concerns. Res Nurs Health 2004; 27(1), p.40-51.

15. Moetlo GJ, Pengpid S, Peltzer K. An evaluation of the implementation of integrated community home- 
based care services in Vhembe District, South Africa. Indian J Palliat Care. 2011; 17(2), p.137-142.

16. Department of Health, South African guidelines for healthy eating for adults and children over the age of seven years, Department of Health. Pretoria. 2004.

17. Leedy PD, Ormrod JE. Qualitative research. Practical Research: Planning and Design. 2014;141-72.

18. Mupfumira IM, Mawarire P. Home based care for HIV and AIDS patients: A case of Rujeko $C$ suburbs Masvingo urban Zimbabwe. IJARPED. 2013; 2(2), p.99-112.

19. Irungu MS. Nutrition knowledge and practices of trained home based care volunteers for people living with HIV/AIDS in Kakamega District Kenya, MSc dissertation. 2007. Dept. of Food Science, Nutrition and Technology, Applied Human Nutrition Unit, University of Nairobi.

20. Rendall-Mkosi K, Phohole M. Integrating paediatric palliative care into home-based care: An evaluation of three home-based care projects, Health System Trust. Durban. 2005.

21. Akintola G. Home-based care: A gender analysis of informal caregiving for people living with HIV/AIDS in a semi-rural South African setting. In: Y. League, T., Day, C. Centre, editors. How long as a volunteer at community outreach center. Policy Brief. 2004..

22. Madzingira N, Mamimine P, Chingandu L, Mkaronda J, Marimo N. Looking back, mapping forwards: Research findings on home-based care in Zimbabwe. SAfAIDS. Harare. 2007.
23. Mieh TM, Iwelunmor J, Airhihenbuwa CO. Homebased caregiving for people living with HIV and AIDS in South Africa. J Health Care Poor Underserved. 2013; 24(2), p.697-705.

24. Ryan C. Caregivers of the elderly: Lack of nutrition knowledge. J Nutr Elder. 1998; 17(2), p.35-44.

25. Uys LR. The practice of community caregivers in a home-based HIV/AIDS project in South Africa. Journal of Clinical Nursing. 2002; 11(1), pp.99-108.

26. Aitken J, Kemp J. HIV and AIDS, equity and health sector personnel in Southern Africa, Regional Network for Equity in Health in Southern Africa (EQUINET) in cooperation with Oxfam GB, EQUINET Discussion Paper Number 12. September 2003.

27. Department of Health, Integrated community home-based care in South Africa: A review of the model implemented by the Hospice Association of South Africa, Department of Health. Pretoria. 2002.

28. Campbell C, Foulis C. Creating contexts for effective home-based care of people living with HIV/AIDS. Curationis. 2004;27(3), p.5-14.

29. Department of Health. National guidelines on home-based care and community-based care. National Department of Health. Pretoria, South Africa: Government press. 2001.

30. Mohammed N, Gikonyo J. Operational challenges: Community home based care (CHBC) for PLWHA in multi-country HIV/AIDS Programs (MAP) for Sub-Saharan Africa, Africa Region working paper series no. 88. World Bank, Washington DC. 2005. 